\title{
Acute Spontaneous Intra Cranial Haemorrhage- A Clinical Study of 75 Cases at Lucknow
}

\author{
Dr. DK Vatsal, MS, $\mathrm{Mch}^{1}$, Dr Rajeev Kainth, MS, $\mathrm{Mch}^{2}$, \\ Dr. Mazhar Husain MS, $\mathrm{Mch}^{3}$, \\ ${ }^{1}$ Assistant Professor Of Neurosurgery, Department Of Surgery, Hind Institute Of Medical Sciences, Safedabad, \\ Barabanki. \\ ${ }^{2}$ Assistant Professor, Department Of Surgery, Rama Medical College And Hospital, Kanpur. \\ ${ }^{3}$ Ex. Prof. \& Head, Department Of Neurosurgery, KG Medical University, Lucknow.
}

\begin{abstract}
:
Objective: To study clinical features among the patients of acute spontaneous intra cranial haemorrhage (ASICH).

Methods: This was a cross-section observational study. The study included 75 patients of ASICH belonging to different age groups and both sexes. A detailed history of all the patients was taken. The signs and symptoms elaborated were: headache, nausea/vomiting, altered sensorium, convulsion, neorological deficit etc. Computed tomography $(C T)$ of head including plain and contrast was done in all the patients.

Results: Out of the total 75 of ASICH patients, $56 \%$ were males and $44 \%$ were females. The most affected age groups was 51-60 years (44\%). Headache was the most common symptom (81.3\%) among the patients. Nausea/vomiting was the second most common symptom (46.7\%). The etiological findings showed that hypertension was found among $46.7 \%$ patients. Aneurysm was observed in $17.3 \%$. Thalamic/putaminal haematoma was the commonest CT finding among the ASICH patients (41.3\%). Lobar haematoma was found to be the second most common CT finding (29.3\%).

Conclusion: The commonest cause of ASICH was hypertension. Anterior communicating, anterior cerebral artery junction were the commonest site for aneurysm.
\end{abstract}

Keywords: Intra cranial haemorrhage, Clinical profile, Computed tomography

\section{Introduction}

Cerebrovascular diseases are the third leading cause of death after heart disease and cancer in developed countries. They also come first in terms of causing death and disability in neurologic diseases in adults (Sacco, 1997).Spontaneous intra-cerebral hemorrhage (ICH) which is defined as spontaneous rupture of the intra-cerebral small vessels following cerebral vessel wall degeneration due to frequent chronic hypertension or rarely to cerebral amyloid angiopathy, has an incidence of 15-19/100,000/year and a 30-day mortality of 40$50 \%$. The risk factors for ICH are identified as hypertension, advancing age, male sex, excessive alcohol intake, anticoagulation therapy, smoking, and diabetes. To determine these risk factors is very important in terms of developing preventative measures (Asuman et al, 2013).

Radiological studies such as computerized tomogram (CT) scan and magnetic resonance imaging have facilitated in locating and assessing the extent of insult precisely and deciding prognosis of the patient. Although several randomized therapeutic trials for ICH have been published, neither surgical nor medical treatments have been shown conclusively to benefit patients (Mendelow et al, 2005; Fernandes et al, 2000). However, early surgical intervention has shown mild statistically significant improvement in clinical outcome (Mendelow et al, 2013). Prognostic factors for predicting functional outcome and mortality thus play a major role in determining the treatment outcome (Nilsson et al, 2002; Hemphill, 2001). There has been considerable interest in predicting outcome after ICH and a number of studies have investigated the relationship of various clinical and radiological factors and poor outcome (Bhatia et al, 2013). The objective of this study was to study the clinical features among the patients of acute spontaneous intra cranial haemorrhage (ASICH).

\section{Material And Methods}

This was a cross-section observational study. The present study was conducted on all the cases of acute spontaneous intra cranial haemorrhage (ASICH) presenting to the Department of Neurosurgery, KG Medical University, Lucknow. The consent was taken from each case before including in the study.

The study included 75 patients of ASICH belonging to different age groups and both sexes. A detailed history of all the patients was taken. The signs and symptoms elaborated were: headache, nausea/vomiting, altered 
sensorium, convulsion, neorological deficit etc. Computed tomography (CT) of head including plain and contrast was done in all the patients.

The results are presented in frequencies and percentages. All the analysis was carried out on SPSS 16.0 version (Chicago, Inc., USA).

\section{Results}

Out of the total 75 of ASICH patients, $56 \%$ were males and $44 \%$ were females. The most affected age groups was 51-60 years (44\%) followed by 31-40 (20\%), 21-30 (16\%), 41-50 (6.7\%), 11-20 \& 61-70 (5.3\%) and $0-10(2.7 \%)$. ASICH was higher in males than females in almost all the age groups except $41-50$ years where females were more affected than males (Table-1).Headache was the most common symptom (81.3\%) among the patients. Nausea/vomiting was the second most common symptom $(46.7 \%)$. However, altered sensorium was the third most common symptom (38.7\%). Speech difficulty was least common symptom (2.7\%) (Table-2).The duration of ASICH was 3-4 days in 30.7\% and 5-6 days in 20\% patients. However, the duration of ASICH was 0-2 days in 14.7\% patients and 7-8 days in 13.3\% patients (Table-3). The etiological findings showed that hypertension was found among $46.7 \%$ patients. Aneurysm was observed in $17.3 \%$. The percentage of other etiological findings was less than $10 \%$ (Table-4). Thalamic/putaminal haematoma was the commonest CT finding among the ASICH patients (41.3\%). Lobar haematoma was found to be the second most common CT finding (29.3\%) and Subarachnoid haematoma was the third most common CT finding (26.7\%). Cerebellar haematoma and Brain stem haematoma were the least common CT finding each constituted 2.7\%. CT finding was found to be normal in $2.7 \%$ patients (Table-5).

\section{Discussion}

Spontaneous ICH is associated with a high mortality and morbidity. The incidence is estimated at 24.6 cases per 100,000 people annually, with mortality rates of $40 \%$ at 1 month and $54 \%$ at 1 year, with only $12 \%$ to $39 \%$ of patients recovering long-term functional independence (van et al, 2010).' Spontaneous ICH is responsible for $50 \%$ of strokes in children, whereas it accounts for only $15 \%$ of strokes in adults. In adults, hypertension is the most common cause of ICH, whereas in children, secondary factors such as vascular malformations cause ICH, although there are still few pediatric studies (Beslow et al, 2010). ICH is an important cause of morbidity and mortality in hemophilia patients, with an incidence ranging from 2.2 to $7.5 \%$ (Ghosh et al, 2005). Clotting factor replacement therapy, emergency neurosurgery and rapid and appropriate airway management are essential in comatose patients (Beslow et al, 2014). A multidisciplinary approach involving hematologists, neurosurgery and intensive care personnel is crucial for achieving a favorable outcome. The decrease in 30-day mortality is likely related to the introduction of investigation protocols, early diagnosis and management strategies for these patients, including monitoring in ICU environments (Stevens et al, 2015).

In the present study, uut of the total 75 of ASICH patients, $56 \%$ were males and $44 \%$ were females. The most affected age groups was 51-60 years (44\%) followed by 31-40 (20\%), 21-30 (16\%), 41-50 (6.7\%), 11$20 \& 61-70(5.3 \%)$ and $0-10(2.7 \%)$. ASICH was higher in males than females.

In a study (Siddique et al, 2016), the highest frequency of intracranial hemorrhage was in age range 1630 years that is in 13 out of 25 patients. Male patients showed higher incidence of intracranial hemorrhage (72\%) as compared to females.The most important risk factors for ICH include hypertension (HTN) and cerebral amyloid angiopathy (CAA). HTN-related ICH is more likely to occur in deep structures (Matsukawa et al, 2011) and the risk of ICH increases with increasing blood pressure values (Ariesen et al, 2003). CAA tends to occur in association with advanced age, and CAA-related ICH tends to occur in lobar regions (Maia et al, 2007). In the present study, headache was the most common symptom (81.3\%) among the patients. Nausea/vomiting was the second most common symptom (46.7\%). The etiological findings showed that hypertension was found among $46.7 \%$ patients. Aneurysm was observed in $17.3 \%$. The percentage of other etiological findings was less than $10 \%$.

The acute presentation of ICH can be difficult to distinguish from ischemic stroke. Symptoms may include headache, nausea, seizures and focal or generalized neurologic symptoms. Findings such as coma, headache, vomiting, seizures, neck stiffness and raised diastolic blood pressure increase the likelihood of ICH compared to ischemic stroke, but only neuroimaging can provide a definitive diagnosis (Anderson et al, 2008).

Computed tomography (CT) detects symptomatic ICH within minutes of symptom onset but may lack sensitivity if the bleeding is hyperacute (uncoagulated blood) or CT brain imaging is delayed for more than 1 week after ICH onset (hematoma isodense to brain tissue) (Lovelock et al, 2009). In this study, thalamic/putaminal haematoma was the commonest CT finding among the ASICH patients (41.3\%). Lobar haematoma was found to be the second most common CT finding (29.3\%) and Subarachnoid haematoma was the third most common CT finding (26.7\%). Cerebellar haematoma and Brain stem haematoma were the least common CT finding each constituted 2.7\%. CT finding was found to be normal in $2.7 \%$ patients The reliable detection of an underlying arterial aneurysm, arteriovenous malformation or dural arteriovenous fistula may 
require additional intra-arterial digital subtraction angiography because timely treatment can prevent recurrent ICH (Al-Shahi et al, 2009). Prevention and treatment of cardiovascular risk factors are vital in ICH prevention among young adults. Comprehensive diagnostic work-up and imaging are essential in identifying the underlying cause of ICH.

\section{Conclusion}

The commonest cause of ASICH was hypertension. Anterior communicating, anterior cerebral artery junction were the commonest site for aneurysm.

\section{References}

[1]. Sacco RL. Risk factors, outcomes, and stroke subtypes for ischemic stroke. Neurology. 1997;49:S39-44.

[2]. Asuman Celikbilek, Basak Karakurum Goksel, Gokmen Zararsiz, and Sibel Benli. Spontaneous intra-cerebral hemorrhage: A retrospective study of risk factors and outcome in a Turkish population. J Neurosci Rural Pract. 2013 Jul-Sep; 4(3): $271-277$.

[3]. Fernandes HM, Gregson B, Siddique S, Mendelow AD. Surgery in intracerebral hemorrhage. The uncertainty continues. Stroke 2000;31:2511-6.

[4]. Mendelow AD, Gregson BA, Fernandes HM, Murray GD, Teasdale GM, Hope DT, et al. Early surgery versus initial conservative treatment in patients with spontaneous supratentorial intracerebral haematomas in the international surgical trial in intracerebral haemorrhage (STICH): A randomised trial. Lancet 2005;365:387-97.

[5]. Mendelow AD, Gregson BA, Rowan EN, Murray GD, Gholkar A, Mitchell PM; STICH II Investigators. Early surgery versus initial conservative treatment in patients with spontaneous supratentorial lobar intracerebral haematomas (STICH II): A randomised trial. Lancet 2013;382:397-408.

[6]. Nilsson OG, Lindgren A, Brandt L, Säveland H. Prediction of death in patients with primary intracerebral hemorrhage: A prospective study of a defined population. J Neurosurg 2002;97:531-6.

[7]. Hemphill JC $3^{\text {rd }}$, Bonovich DC, Besmertis L, Manley GT, Johnston SC. The ICH score: A simple, reliable grading scale for intracerebral hemorrhage. Stroke 2001;32:891-7.

[8]. Bhatia R, Singh H, Singh S, Padma MV, Prasad K, Tripathi M, Kumar G, Singh MB. A prospective study of in-hospital mortality and discharge outcome in spontaneous intracerebral hemorrhage. Neurol India 2013;61:244-8

[9]. van Asch CJ, Luitse MJ, Rinkel GJ, van der Tweel I, Algra A, Klijn CJ. Incidence, case fatality, and functional outcome of intracerebral haemorrhage over time, according to age, sex, and ethnic origin: a systematic review and meta-analysis. Lancet Neurol. 2010;9(2):167-76

[10]. Beslow LA, Licht DJ, Smith SE, Storm PB, Heuer GG, Zimmerman RA, et al. Predictors of outcome in childhood intracerebral hemorrhage: a prospective consecutive cohort study. Stroke. 2010;41(2):313-8.

[11]. Ghosh K, Nair AP, Jijina F, Madkaikar M, Shetty S, Mohanty D. Intracranial haemorrhage in severe haemophilia: prevalence and outcome in a developing country. Haemophilia. 2005;11(5):459-62.

[12]. Beslow LA, Ichord RN, Gindville MC, Kleinman JT, Bastian RA, Smith SE, et al. Frequency of hematoma expansion after spontaneous intracerebral hemorrhage in children. JAMA Neurol. 2014;71(2):165-71.

[13]. Stevens RD, Shoykhet M, Cadena R. Emergency Neurological Life Support: Intracranial Hypertension and Herniation. Neurocrit Care. 2015;23 Supp 2:76-82.

[14]. Siddique U, Gul H, Nawab K, Roghani IS, Afridi Z, Dawar NA. Intracranial hemorrhage in patients with head trauma On computed tomography scan. PJR July - September 2016; 26(3)

[15]. Matsukawa H, et al. Factors associated with lobar vs. non-lobar intracerebral hemorrhage. Acta Neurologica Scandinavica. 2011.

[16]. Ariesen MJ, et al. Risk Factors for Intracerebral Hemorrhage in the General Population. Stroke. 2003;34(8):2060-2065

[17]. Maia LF, Mackenzie IRA, Feldman HH. Clinical phenotypes of Cerebral Amyloid Angiopathy. Journal of the Neurological Sciences. 2007;257(1-2):23-30.

[18]. Anderson CS, et al. Intensive blood pressure reduction in acute cerebral haemorrhage trial (INTERACT): a randomised pilot trial. The Lancet Neurology. 2008;7(5):391-399.

[19]. Lovelock CE, Anslow P, Molyneux AJ, Byrne JV, Kuker W, Pretorius PM, Coull A, Rothwell PM: Substantial observer variability in the differentiation between primary intracerebral hemorrhage and hemorrhagic transformation of infarction on CT brain imaging. Stroke 2009;40:3763-3767.

[20]. Al-Shahi Salman R, Labovitz DL, Stapf C: Spontaneous intracerebral haemorrhage. BMJ 2009;339:b2586.

Table-1: Age and sex distribution of acute spontaneous intra cranial haemorrhage cases

\begin{tabular}{|l|c|c|c|c|c|c|}
\hline \multirow{2}{*}{$\begin{array}{c}\text { Age in } \\
\text { years }\end{array}$} & \multicolumn{2}{|c|}{ Male } & \multicolumn{2}{c|}{ Female } & \multicolumn{2}{c|}{ Total } \\
\cline { 2 - 7 } & No. & \% & No. & \% & No. & \% \\
\hline $0-10$ & 1 & 50.0 & 1 & 50.0 & 2 & 2.7 \\
\hline $11-20$ & 2 & 50.0 & 2 & 50.0 & 4 & 5.3 \\
\hline $21-30$ & 6 & 50.0 & 6 & 50.0 & 12 & 16.0 \\
\hline $31-40$ & 9 & 60.0 & 6 & 40.0 & 15 & 20.0 \\
\hline $41-50$ & 1 & 20.0 & 4 & 80.0 & 5 & 6.7 \\
\hline $51-60$ & 21 & 63.6 & 12 & 36.4 & 33 & 44.0 \\
\hline $61-70$ & 2 & 50.0 & 2 & 50.0 & 4 & 5.3 \\
\hline Total & 42 & 56.0 & 33 & 44.0 & 75 & 100.0 \\
\hline
\end{tabular}

Table-2: Distribution of signs and symptoms of acute spontaneous intra cranial haemorrhage cases

\begin{tabular}{|l|c|c|}
\hline Signs and Symptoms* & $\begin{array}{c}\text { No. } \\
(\mathbf{n = 7 5})\end{array}$ & \% \\
\hline Headache & 61 & 81.3 \\
\hline Nausea/Vomiting & 35 & 46.7 \\
\hline Altered sensorium & 29 & 38.7 \\
\hline Convulsion & 5 & 6.7 \\
\hline
\end{tabular}


*Multiple response

\begin{tabular}{|l|c|c|}
\hline Neorological deficit & 20 & 26.7 \\
\hline Neck rigidity & 17 & 22.7 \\
\hline Photophobia & 3 & 4.0 \\
\hline Speech difficulty & 2 & 2.7 \\
\hline
\end{tabular}

Table-3: Distribution of duration of acute spontaneous intra cranial haemorrhage cases

\begin{tabular}{|l|c|c|}
\hline \multicolumn{1}{|c|}{ Duration in days } & $\begin{array}{c}\text { No. } \\
(\mathbf{n = 7 5})\end{array}$ & $\mathbf{\%}$ \\
\hline $0-2$ & 11 & 14.7 \\
\hline $3-4$ & 23 & 30.7 \\
\hline $5-6$ & 15 & 20.0 \\
\hline $7-8$ & 10 & 13.3 \\
\hline $9-10$ & 8 & 10.7 \\
\hline $11-12$ & 6 & 8.0 \\
\hline $13-14$ & 0 & 0.0 \\
\hline$>14$ & 2 & 2.7 \\
\hline
\end{tabular}

*Multiple response

Table-4: Distribution of etiology of acute spontaneous intra cranial haemorrhage cases

\begin{tabular}{|l|c|c|}
\hline \multicolumn{1}{|c|}{ Etiology } & $\begin{array}{c}\text { No. } \\
(\mathbf{n = 7 5 )}\end{array}$ & \% \\
\hline Hypertension & 35 & 46.7 \\
\hline Aneurysm & 13 & 17.3 \\
\hline AVM & 5 & 6.7 \\
\hline Tumour & 1 & 1.3 \\
\hline Vasculopathy & 0 & 0.0 \\
\hline Coagulopathy & 0 & 0.0 \\
\hline Unexplained & 21 & 28.0 \\
\hline
\end{tabular}

Table-5: Distribution of CT findings of acute spontaneous intra cranial haemorrhage cases

\begin{tabular}{|l|c|c|}
\hline \multicolumn{1}{|c|}{ CT findings* } & $\begin{array}{c}\text { No. } \\
(\mathbf{n = 7 5 )}\end{array}$ & \% \\
\hline Lobar haematoma & 22 & 29.3 \\
\hline Thalamic/putaminal haematoma & 31 & 41.3 \\
\hline Cerebellar haematoma & 2 & 2.7 \\
\hline Brain stem haematoma & 2 & 2.7 \\
\hline Intraventicular haematoma & 10 & 13.3 \\
\hline Subarachnoid haematoma & 20 & 26.7 \\
\hline Normal & 2 & 2.7 \\
\hline
\end{tabular}

*Multiple response 